\title{
D'hulst, L., \& Gambier Y. (Eds.). (2018). A history of modern translation knowledge: Sources, concents, effects. Amsterdam: John Benjamins. 475 pp.
}

In A History of Modern Translation Knowledge, a fuller understanding is sought of the discourses, structures and infrastructures that have contributed to the advancement of knowledge in the field of translation. For several reasons, the book will not leave the reader indifferent. On the one hand, this book can be seen as a corollary to the four volumes of the Handbook of Translation Studies (HTS) series (Gambier \& Van Doorslaer, 2010-2013), which aim to provide access to a vast body of knowledge on topics, traditions and methods in translation studies. In a way, the publication by D'hulst and Gambier bears some resemblance to HTS: it is hailed in the blurb texts as a reference source for young researchers who wish to find their way in translation studies. Indeed, as a whole, the many discourses, set out in 55 chapters and visualised in synoptic figures and lists, form a fairly comprehensive account of what makes up the discipline that was willed into being in the 1970s. On the other hand, $A$ History of Modern Translation Knowledge distinguishes itself from standard reference works in translation studies. Steeped in the philosophy of science and in modern historiography, this publication refuses to present the history of translation knowledge as a Whig history, a lockstep march towards truth and enlightenment. The book marks a clean break with the idealistic positivism upon which the empirical discipline of translation studies is premised and which permeates the countless contributions to reference works like HTS. The boundaries of translation studies are deliberately blurred and continuously transgressed, in an attempt to challenge the distinction between what is thought to belong to the past, knowledge that is deemed obsolete and sometimes arcane, and what is part of the present. The book clearly illustrates how both forms of knowledge (past and present) co-exist and coalesce in modern translation theory. By doing so, the book does away with the "pureness" of scientific findings and directs the readers' attention to the social, political, ideological, technological, physical, digital and economic conditions, under which findings, be they scientific or not, have been and are being presented as "facts". In a nutshell, $A$ History of Modern Translation Knowledge paints a somewhat unsettling historical (or, rather, historiographical) picture of what can be considered knowledge of and about translation.

The structure of the book is patterned upon Burke's seven stages of knowledge-building and knowledge-consolidation processes. The sequences described by Burke are the following: (1) generation of knowledge, (2) mapping of knowledge, (3) internationalisation of knowledge, (4) historizing of knowledge, (5) analysis of knowledge, (6) dissemination of knowledge and (7) application of knowledge. Each of the seven parts of A History of Modern Translation Knowledge is introduced by the editors and contains 5 to 10 chapters that shed light on different aspects of the process under investigation. Some chapters are relatively long (e.g., Hurtado-Albir's chapter on training: 14 pages), whereas other chapters are extremely short (e.g., Agorni's chapter on localism: 2 pages).

In Part 1, attention is drawn to the ways in which knowledge of and about translation has been generated in the past, mainly, but not exclusively, in pre- or extra-scientific discourse. With translation being an indisputable object of intellectual observation, it comes as no surprise that the part on knowledge generation contains chapters on the conceptualisation of translation. The age-old debate about the nature of translation runs parallel to the discussion about conceptual contiguousness: with references to pseudo-translations, pseudo-originals, 
auto-translation and indirect translation, the conceptual boundaries of translation are explored and, in one fell swoop, extended. Another aspect that warrants attention in the debate on the nature of translation is the metaphorisation of translation. In the part on knowledge generation, metaphorisation is looked at from two different angles. First, the focus falls on the numerous tropes and metaphors that theorists and theoreticians alike have come up with to describe and define translation (Chapter 1.2.). Subsequently, John $\varnothing$ demark and Eivind Engebretsenpresent translation as a metaphor used predominantly to describe processes in disciplines such as history, anthropology and medicine. Klaus Kaindl shows that metaphoric imagery can also be extended through fictional representations of translators and translation. These representations are also included as potential sources of translation knowledge. In a similar fashion, translation also becomes bound up with religion: inspiring accounts are offered, by Claire Placial, of the mythologisation of translation, which revolves mainly around "the origin of translation", and, by Douglas Robinson, of the tabooing of the translational act itself as a direct result of the sacralisation and mystification of mainly religious texts. Towards the end of Part I, Stecconi explains how translation has become enmeshed in the fabric of one (inter)discipline, semiotics, by presenting translatability as a sine qua non of sign-action. In the final chapter of Part I, he explains how translation has always played a pivotal role in another (inter)discipline, namely rhetoric, as it is presented as a means to gain knowledge of and insight into culture-specific rhetoric habits.

Part 2 of the book deals with the mapping of knowledge. The reason for including a part on this particular subject is that traditional reference works do not give due consideration to the factors that condition and shape the knowledge of and about translation. Among the material factors, technology is cited by D'hulst and Gambier (p. 101) as a major facilitating ánd constraining factor in the production of (modern) translation knowledge. In his chapter on print history, Bachleitner considers the decisive role the printing press has played in the production and distribution of translated texts, as well as its effect on the sociocultural trends and authorities that have exerted tremendous influence over text-selection processes. In the following chapter, written by Folaron, the impact of new communication technology is discussed. To state that these technologies, ranging from social media through translation management systems, all the way to open-source translation software, have redefined the contours of translation would be a rather cautious claim. In Dunne's contribution on localisation, for example, it is shown that the convergence of translation and localisation has changed the way in which (translated) texts are perceived. Instead of "documents", localisers tend to translate decontextualized chunks of information. Technology has not only left an indelible mark on the form and distribution of translation, it also continually conditions the way in which knowledge about translation is channelled. The increasingly important role of non-traditional forms of knowledge circulation is also discussed by Folaron. In her chapter on the circulation and spread of knowledge, she emphasises the fact that, in modern contexts, there are countless ways to share knowledge. Webinars, interviews, LSP case studies, blogs and discussion forums are listed among the modern means of knowledge circulation. RoviraEsteva and Aixela also draw attention to the use of technology in academic discourse. Through the use of bibliometric tools, for instance, translation scholars can gather quantitative data on translation flows. The same tools, however, also play an increasingly important role in the selection and reception of scholarly output: Bibliometrics shows us, and tells us, which ideas are most likely to become mainstream, and which scholarly knowledge will probably be relegated to the fringes of academic discourse. The networks of relations between agents and 
organisations that control the production and transfer of knowledge on different levels take centre stage in the contribution by D'hulst. It is but a small step from agents in academic discourse to "turns" in translation studies, the topic of the final contribution in this part written by Snell-Hornby. Far from destabilising knowledge about translation, these turns tend to leave room for some continuity.

In Part 3, translation knowledge and know-how are observed through the prism of space. As mentioned by the volume editors, the view that internationalisation and translation are inextricably linked is widely shared in translation studies (p. 151). The need for mediation is felt whenever a nation looks beyond its own borders and when two cultures enter into contact, be it friendly or not. In his chapter on globalisation, Cronin explains that, in our globalised world, translation has become endowed with special powers, as it seems to facilitate the operation of institutions on a global scale but, at the same time, reveals the limits of cultural mediation. Globalisation also demands reinvigorated attention to universal languages and language structures, as is illustrated in Bennett's chapter on universal language. International contact has served as a catalyst for translation theory as well. Multilingual settings prompt language users and translators to think about the objectives of intercultural communication and about methods that permit them to fulfil those objectives. In Tymoczko's chapter about the impact of internationalisation on translation theory, it is shown that a take on the history of translation knowledge allows for a better understanding of the development of translation studies as a discipline of "thought". In Van Doorslaer's chapter on eurocentrism, it is argued that the fledgling discipline of the 1970s viewed translation through its Eurocentric lens, employing notions such as "equivalence" and "fidelity", but that translation studies started intercontinentalising in the 1990s, welcoming new ideas and concepts that seemed inconceivable in the past. Again, this factual displacement of ideas across boundaries urges us to critically investigate the discursive and political means that have been used to internationalise knowledge of and about translation (e.g., through the standardisation of training programmes). In the standardisation process, the roles of private, national and international institutions are paramount. These roles are covered by Gambier in the chapter Institutionalization of Translation Studies. Part 3 is brought to a close with a chapter by Meylaerts and and a chapter by Merkle on the policies and official politics that have not only contributed to the spread and valuation of translation, but that, because of their culturalpolitical nature, have also constituted a major impediment to the exchange of cultural knowledge and values (e.g., censorship).

In Part 4, the history of translation is described in temporal terms. A temporal take on history sounds rather pleonastic and therefore redundant: when looking at the history of translation knowledge, one always takes into account the passing of time. However, what is often overlooked in historical overviews is that every description of the evolution of translation knowledge is determined by a particular historical model. Reference sources in translation studies have shown that it is convenient to adopt an epochal or periodical approach to translation and translation theory. In recent years, fair criticism has been raised against this periodical approach, since the past is mostly presented in teleological terms, to fit a narrative of progress. The contributions by Wakabayashi (on microhistory, and connected history and histoire croisée) and Valdeón (on comparative history) show that different historical models can be used to nuance our understanding of the past. Through microhistories that focus on specific situations in which "ordinary" translation tasks are carried out, abstract and general claims about translation can be sustained, rejected or refined (Chapter 4.3). In comparative 
history, ideational, ideological and situational similarities and dissimilarities between two or more societies or periods are scrutinised (Chapter 4.4). In modern comparative translation history, scholars are urged to provide finer-grained analyses of the roles of translators in ideological displacement and modification. Through the description of connected history, the limitations of bilateral and linear approaches to intercultural encounters, which tend to simplify notions of cultural centrality and periphery, can be removed, as research on connected history focuses on multilateratily and diffuseness on various levels and in diverse directions (Chapter 4.5). A number of chapters in Part 4 also bring into view the structuring and preservation of translation history: Kujamäki's contribution shows that, due to the invisibility or effacement of translation activities in many archives, document research is often problematic. McDonough Dolmaya's chapter shows that the endeavours to preserve oral accounts of historical relevance (e.g., interviews with translators) are also fraught with difficulties-not only difficulties of a technical nature. Part 4 ends with D'hulst's thoughtprovoking chapter on counterfactual history. Although counterfactual histories are largely of a conjectural and speculative nature, they are seen as a good means to avoid the Whig fallacy. D'hulst admits that these histories do not pay sufficient heed to causal complexity, but they alter the perspective on translation by emphasising "routes not taken" (pp. 279-280).

Part 5 brings the history of knowledge analysis in translation to the fore. Knowledge analysis is described by the editors as the transformation of raw data or information into knowledge (often theory) (p. 285). In this part, the editors have roughly distinguished between three categories in the analysis of translation: pre-translation, translation (as a product and a process) and post-translation. Many analytical practices that are discussed in this part are textbased or text-driven. In the first chapter by Tahir Gürçağlar, the focus is on the ways in which translated texts have come to inform knowledge of and about translation, but also on the more recent interset in the paratextual surroundings of the translated text (i.e., peritexts and epitexts). Munday's chapter on translation analysis sets out frameworks and vocabulary that have been developed with a view to identifying, classifying and discussing features and patterns that pertain to source and target texts. Stefanink and Bălăcescu discuss hermeneutics and Koskinen zeroes in on deconstruction. Hermeneutics and deconstruction are singled out as text-based approaches that, due to the unpopularity of philosophical musings in modern translation theory, are often downplayed, but that are said to have added value as they urge analysts to critically investigate the logical and verbal foundations of the text in front of them as well as their own implication in the fabrication of meaning through interpretation. Ehrensberger-Dow diverts the attention away from the texts and towards the translation process. This process was initially captured in protocols and dialogues but can now be registered with less intrusive methods (e.g., keylogging, screen recording, eye-tracking). As can be inferred from Tahir Gürçağlar's chapter on translated texts and paratextuality, translation analysis not only warrants "simple" text-based research, it also requires us to think about the context in which translations are embedded. To ensure that translation is not taken out of context, a myriad of methods and approaches are set forth in the chapters on "localism" (Agorni), "sociological models" (Buzelin) and "[thin] ethnography" (Flynn). With the aim of broadening the scope of translation analysis even further, Simon also draws attention to sites of translation, places where there is, for whatever reason, heightened language awareness. A few examples of contact zones that have been identified as so-called "translation spaces" are airports, train stations, hotels and markets. It is not until the final chapter in Part 5, a chapter written by Von Flotow, that attention is paid to the analysis of translation as a site of activism. 
She explains how gender is reflected in translation and how translators have staked out their gender positions through the act of translation.

As Holmes (1988, p. 67) noted in The Name and Nature of Translation Studies, scientific disciplines usually find their origins in research questions, methods, models and paradigms that are relevant or even pertain to adjacent areas of research. In translation studies, the influence of contiguous disciplines has always been undeniable. However, it is abundantly clear from the contributions in Part 5 that translation studies does not or no longer finds itself in the so-called "imperialistic stage" of interdisciplinarity. Most chapters in Part 5 seem to suggest that translation studies remains stuck in the "importing stage". For instance, in the chapters on linguistics (Vandepitte, Jooken, Maier, \& Zheng) and cognitive research (Shreve), little to no mention is made of true interdisciplinary exchange; translation studies seems to borrow freely and heavily from numerous branches of linguistics and cognitive sciences. The perspective on the disciplinary status changes in the chapter on literary research, where Delabastita illustrates how the "prevailing donor and receptor roles are reversing" (p. 376). The issues of mutual clarification, conceptual inclusion and disciplinary synergy are also addressed in the chapters on communication studies (Loenhoff) and legal history (Dullion). These three chapters, along with the chapters on expansions (Ch. 1.8), semiotics (Ch. 1.9) and rhetoric (Ch. 1.10), show us that approaches that have been developed in translation studies and findings that have ensued from these approaches are slowly working their way into adjacent disciplines.

The final part of the book revolves around the application of knowledge. As any self-respecting discipline, translation studies does not seem to consider it its proper task to produce only knowledge that can be considered "useful" (see Holmes 1988). However, it seems safe to maintain that the applicability and instrumentalisation of knowledge is increasingly valued. Nowadays, terms such as professionalisation and valorisation are ubiquitous in curricular design and research proposals. A context in which practices are gradually becoming more knowledge-informed and even research-informed is training. For this reason, it comes as no surprise that training and learning are central in the chapter on the application of knowledge. Analogous to comparative rhetoric, language learning, a topic that is discussed by Laviosa, has always sought ways to put translation to good use: by integrating translation into language learning, knowledge about verbal behaviour patterns in languages, correctness, etc. can be acquired. The knowledge generated through the act of translation/mediation is believed to foster communicative competence. As, Hurtado Albir has shown, the instrumentalisation of knowledge is most noticeable in the domain of translator training: over time, both translation knowledge, ranging from processual knowledge through domain-specific knowledge to knowledge about competence acquisition/evaluation, and knowledge generated in educational sciences have come to professionalise training programmes in translation at a rapid pace. Evaluation and assessment are also discussed in a separate chapter, written by Angelelli. She recognises that evaluation and assessment methods have evolved in the past decades and that this evolution is a direct result of insights yielded through translation research, but she also emphasises the inherent instability of test constructs. Despite the successive fashions and frills in translation studies, attempts to reduce the experiential element in assessment to an acceptable level do not seem to have been hugely successful. The final chapter of the book is on translation ethics. In this chapter, Chesterman shows that ethics has always been at the heart of translation theory. Knowledge on ethics has long centred on the nature of the translated text. This long-standing tradition has been challenged 
in recent years, in theories that take heed of contextual factors and/or professional aspects. Paradoxically, the recent trends in translation theory are not reflected in professional guidelines that have seen the light in past decades (e.g., FIT's 'Translator's Charter', AlIC's 'Code of Professional Ethics'). The fact that the field of professional translation ignores the armchair theorising of specialists in translation ethics (Pym, Venuti, Koskinen, to name but a few) draws the reader's attention to the fact that knowledge about and of translation is always embedded in a context, and even, up to a point, contingent on that context.

On the whole, A History of Modern Translation Knowledge is an extremely successful attempt to trace or outline the history of modern thinking about translation, a history that, despite Holmes's (1988) and Pym's (1998) calls to action, has remained largely undocumented. It puts the evolution of many research strands in and outside of translation studies into perspective and sensitises the reader to the complexity of knowledge processes - as well as to the need for research in translation history. However, this book may also instil a sense of discontent or unease in the reader. Although the editors have readily avoided numerous epistemological traps and have embraced contingency in knowledge processes, by acknowledging their indebtedness to Burke, Levi-Strauss, and Latour and Woolgar, this book urges its readership (scholars, trainers, students) to ponder the ways in which the proverbial serpent tends to bite its own tail. What can be seen as the major strength of this book can be easily turned into a major weakness. A History of Modern Translation Knowledge presents the history of modern translation knowledge as non-linear. It disputes the perceived inferiority of pre-modern forms of knowledge and attests to the unfathomable complexity of the phenomena of translation and translating. By emphasising complexity, the book confronts its reader with the fact that the ultimate goal of translation studies - "to develop a full, inclusive theory accommodating so many elements that it can serve to explain and predict all phenomena falling within the terrain of translating and translation, to the exclusion of all phenomena falling outside it" (Holmes, 1988, p. 73) - is ultimately unattainable, and that the discipline is forced to content itself with no more than prolegomena. By highlighting the non-linearity of translation history and putting pre-modern knowledge on a par with "modern" translation knowledge, the reader may start to believe that even those prolegomena to more comprehensive translation theories cannot even be held to be more truthful than the translation ruminations of the past. If we follow the historiographical logic set out in the introduction of $A$ History of Modern Translation Knowledge to its extreme, the task of translation scholars no longer seems to be that of establishing the truth about translation and translating. Put in Foucauldian terms, their tasks seem to consist of merely bringing about "effects of truth" (effets de vérité) through scientific practices (Foucault, 1977). But what can be said about translation scholars can also be said about translation historians. The sting of the serpent is felt most acutely when the truthfulness of historiographical accounts is scrutinised. By D'hulst and Gambier's own admission, no great claims can be made about the completeness or the accuracy of these accounts; in the end, like all searchers of truth, contributors had to make do with "whatever [was] at hand" ((p. 9). As a result, A History of Modern Translation Knowledge is not only a great work of reference for whoever is interested in translation knowledge, but based on its own premises, it can also be regarded as a great work of "fiction" (in the Nietzschean/Foucauldian sense of the word). 


\section{References}

Foucault, M. (1977). Les rapports de pouvoir passent à l'intérieur des corps [interview with L. Finas]. La Quinzaine littéraire, 247, 4-6.

Holmes, J. S. (1988). Translated!: Papers on literary translation and translation studies. Amsterdam: Rodopi.

Pym, A. (1998). Method in translation history. Manchester: St. Jerome.

Van Doorslaer, L., \& Gambier, Y. (Eds.) (2010-2013). Handbook of Translation Studies: Vol. 1-4. Amsterdam: John Benjamins.

\section{Gys-Walt van Egdom}

Utrecht University

g.m.w.vanegdom@uu.nl 